\title{
Mitral Stenosis: Making the diagnosis
}

\author{
Pooja Prasad MD, Ali Abdulraheem Mahdi MD, Muhammad Majid MD, Patricia Applegate MD, Ezra A. Amsterdam MD, Sandhya \\ Venugopal MD MS-HPEd* \\ Division of Cardiovascular Medicine, Department of Internal Medicine, University of California (Davis) Medical Center, Sacramento, CA, USA.
}

*Corresponding Author: Sandhya Venugopal, Division of Cardiovascular Medicine, Department of Internal Medicine, University of California (Davis) Medical Center, Sacramento, CA, USA.

Received Date: August 03, 2021 | Accepted Date: September 27, 2021 | Published Date: October 05, 2021

Citation: P Prasad, M Majid, P Applegate, Ali A Mahdi, S Venugopal. (2021). Mitral Stenosis: Making the diagnosis. International Journal of Clinical Case Reports and Reviews. 8(5); DOI:10.31579/2690-4861/159

Copyright: (C) 2021 Sandhya Venugopal, This is an open-access article distributed under the terms of the Creative Commons Attribution License, which permits unrestricted use, distribution, and reproduction in any medium, provided the original author and source are credited.

\begin{abstract}
The case of a 60-year-old man illustrates a number of important features of rheumatic heart disease (RHD). The patient's age of presentation was late ( $>50$ yo) and he had no history of predisposing condition for RHD but served in the South Pacific when he was in the US Navy. RHD was limited to mitral stenosis in this patient and his presentation of heart failure was late. His ECG revealed ample evidence of right ventricular enlargement, and echocardiography demonstrated severe mitral stenosis, enlarged right ventricle and right atrium and marked pulmonary hypertension. Because percutaneous balloon mitral valve commissurotomy was precluded by the degree of mitral valve calcification, he underwent successful surgical valve replacement with relief of symptoms. Although RHD is rarely encountered in North America and Europe, it remains a major cause of mortality in the developing nations.

Keywords: rheumatic heart disease; echocardiographic surveillance; mitral stenosis
\end{abstract}

\section{Case Presentation}

A serious heart condition went unnoticed for decades - and then advanced to the point of requiring prompt surgical intervention. The patient, a 60year-old man with no past medical history, presented with a month of progressive dyspnea on exertion. For the past two weeks, he noted increasing orthopnea and intermittent wheezing and palpitations. He was not taking any medications and had not accessed medical care recently. He served in the Navy in Southeast Asia during his teens and twenties, was a current smoker, and was working as a welder and carpenter with carbon and asbestos exposure. His brother died of a myocardial infarction at age 46 years as did his father at age 51 years.

\section{Physical Examination}

The patient was tachycardic (106 bpm); but with otherwise unremarkable vital signs $\left(\mathrm{O}_{2}\right.$ saturation: $96 \%$ on room air, respiratory rate: $18 / \mathrm{min}$, blood pressure: $111 / 75 \mathrm{mmHg}$, temperature: $99.4^{\circ} \mathrm{F}$.) and he was interacting appropriately. He appeared cachectic and on cardiac examination had a regular rhythm, normal $\mathrm{S} 1$ and $\mathrm{S} 2$, and a 2/6 apical systolic murmur with a faint diastolic rumble. P2 was not accented, there was no parasternal lift, and an opening snap was not detected. No gallops or rubs were audible, and his jugular veins were difficult to visualize. The patient's lung sounds were diminished at the bases and there were coarse crackles from bases to mid-back. There were no focal neurologic findings.

Diagnostic StudiesLaboratory data: cardiac troponin: $<0.03 \mathrm{ng} / \mathrm{mL}$ (ref <0.04), brain natriuretic peptide $540 \mathrm{pg} / \mathrm{mL}$ (ref 0-100), albumin 3.5 $\mathrm{g} / \mathrm{dL}$ (ref 3.4-5.4). Fecal occult blood test was negative and thyroid stimulating hormone was $4.4 \mathrm{mU} / \mathrm{L}$ (ref $0.5-4.59 \mathrm{mU} / \mathrm{L}$ ). His electrocardiogram (ECG) demonstrated sinus tachycardia, right axis deviation, right atrial enlargement, and incomplete right bundle branch block, representing a cluster of findings consistent with elevated right ventricular pressure.

A chest radiograph showed moderate bilateral pleural effusions and prominent interstitial markings. Calcifications were present along the aortic arch. Computed tomography (CT) of the chest revealed cardiomegaly, mild pulmonary edema, and large bilateral pleural effusions. Transthoracic echocardiogram (TTE) (Figures 1 and 2) disclosed markedly thickened, severely calcified mitral valve leaflets with commissural fusion and severely decreased excursion indicative of critical mitral valve stenosis (MS) with a mean gradient of $26 \mathrm{mmHg}$ ref $<2 \mathrm{~mm} \mathrm{Hg}$ ), and a calculated mitral valve (MV) area of $0.45 \mathrm{~cm}^{2}$ (ref 4-5 $\mathrm{cm}^{2}$ ). The aortic valve leaflets were calcified and revealed decreased excursion but no evidence of aortic stenosis. Trace aortic regurgitation and mild mitral and tricuspid regurgitation were also noted. Right ventricular systolic pressure was severely elevated to $90-100 \mathrm{mmHg}$ (ref $15-25 \mathrm{mmHg}$ ) and right atrial pressure was mildly increased to 5-10 $\mathrm{mmHg}$ (ref $3 \mathrm{mmHg}$ ). There was also biatrial enlargement, preserved left ventricular ejection fraction, and moderate atherosclerotic plaque in the descending aorta. Coronary angiography demonstrated no obstructive lesions.

CT of the head showed chronic microvascular changes and a left basal ganglia hypodensity, which may reflect prior lacunar infarct. Carotid ultrasound revealed large bilateral calcified plaques resulting in narrowing with doppler findings suggesting $50-79 \%$ bilateral stenosis. 


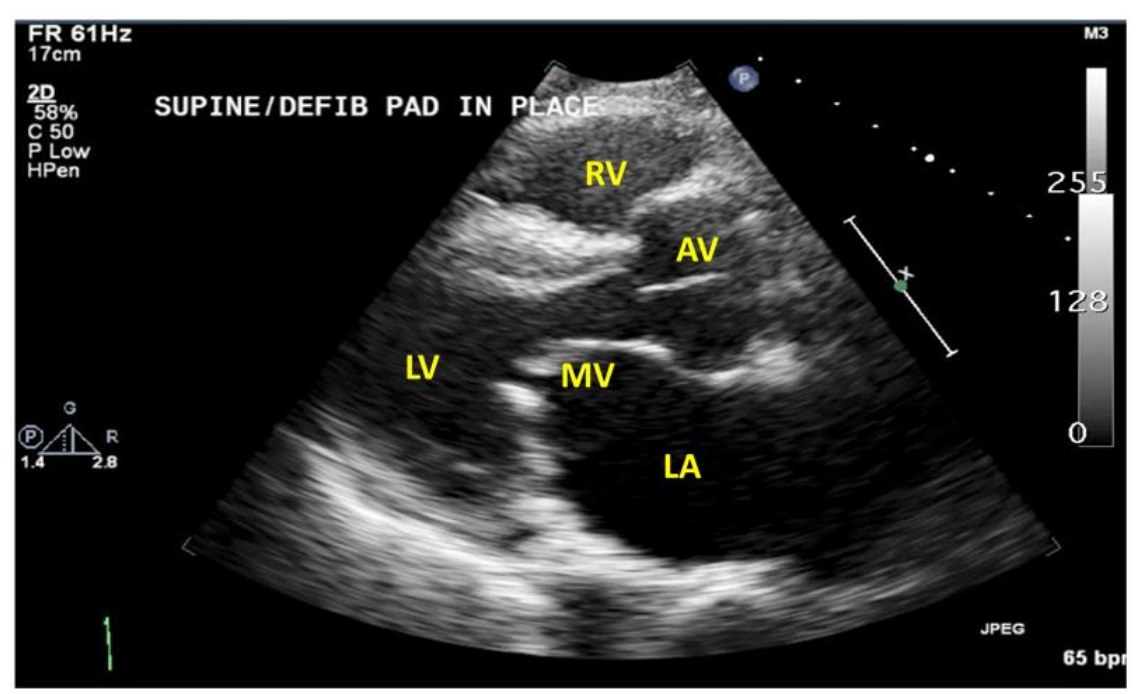

Figure 1: Transthoracic echocardiogram (parasternal long axis view, diastole) demonstrated markedly enlarged LA and mitral stenosis with diastolic doming of thickened leaflets. $L A=$ left atrium; $M V=$ mitral valve; $L V=$ left ventricle; $A V=$ aortic valve; $R V=$ right ventricle

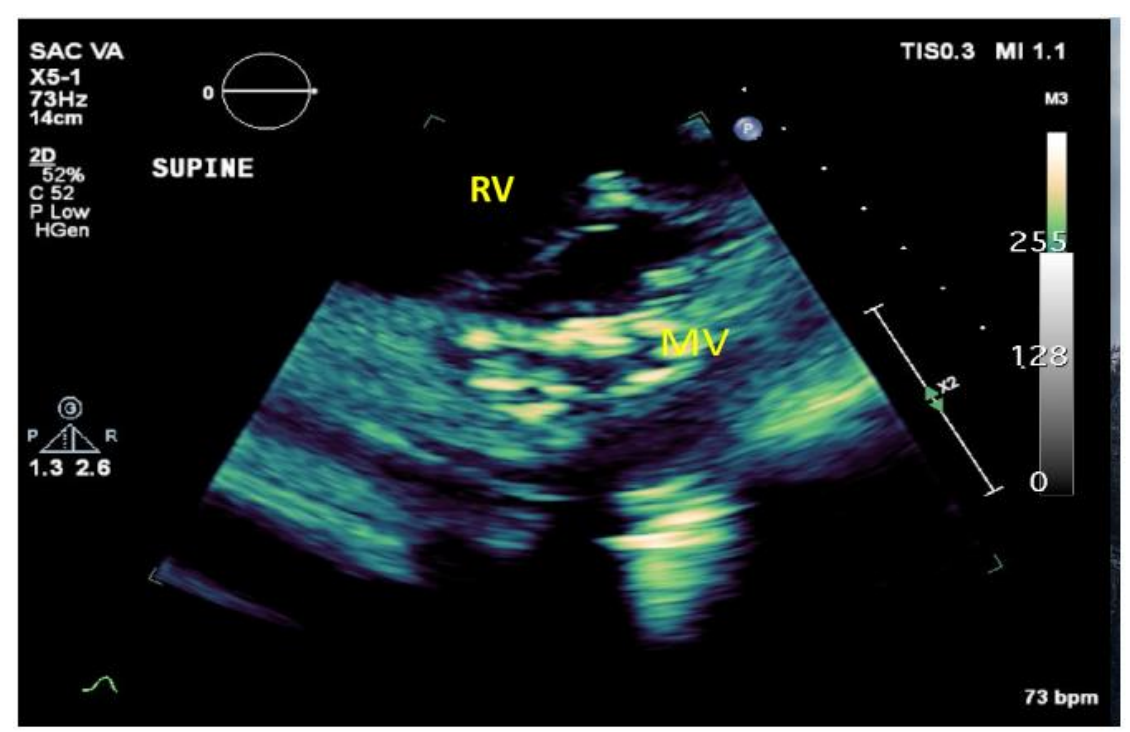

Figure 2: Transthoracic echocardiogram (short axis view of the mitral valve in diastole) demonstrated fusion of both commissures and reduced mitral valve area showing the classic fish mouth deformity. $M V$ : mitral valve; $R V$ : right ventricular cavity.

\section{Discussion}

\section{What is the diagnosis?}

\section{Diagnosis: Rheumatic heart disease with severe mitral stenosis}

The degree of MV leaflet thickening, calcification, commissural fusion and decreased leaflet mobility on the patient's echocardiogram indicated that the severe MS and subsequent heart failure were the result of rheumatic heart disease (RHD). Several aspects of his case are noteworthy. A majority of patients with MS do not have an overt history of antecedent streptococcal infection, which was absent in our patient [1]. Women have a higher prevalence of RHD than men, and patients usually become symptomatic between ages 20-50 years [1]. Therefore, our patient's clinical presentation was late.

RHD is a consequence of repeated valvular damage induced by multiple episodes of acute rheumatic fever (ARF) and/or subclinical rheumatic valve inflammation [1]. In a genetically susceptible host, ARF results from antigenic mimicry in association with an abnormal immune response to group A streptococcal infection involving both humoral and cellular components $^{1}$. These processes usually involve the pharynx and also joints, skin, brain and heart. Mitral valve incompetence is the most common valvular lesion in early stages, but recurrent valvulitis can cause progression to mitral stenosis with bicommissural fusion, which can critically reduce the mitral valve orifice [1]. To maintain blood flow across a stenotic valve, a pressure gradient develops leading to increased left atrial pressure and left atrial dilation,-predisposing patients to pulmonary hypertension and atrial fibrillation. The result of these pathophysiologic derangements includes congestive heart failure and the hazard of systemic embolism [2].

While the global mortality from RHD has declined by approximately $50 \%$ since-1990, this disease remains a significant cause of death with the highest rates in India, China and Pakistan [3]. Echocardiography is the gold standard for diagnosis and has revealed a higher RHD prevalence than thought previously when auscultation of the characteristic murmurs was the main diagnostic tool [4]. The World Heart Federation criteria were developed in order to assist with systematic diagnosis of RHD. For 
MS related to RHD, congenital MV anomalies and nonrheumatic mitral annular calcification must be excluded. The MV morphologic criteria include commissural fusion, anterior MV leaflet thickening (agespecific), chordal thickening, restricted leaflet motion and excessive leaflet tip motion during systole [4].

Treatment of RHD focuses on echocardiographic surveillance and prevention and management of complications, including heart failure, atrial fibrillation, cardio-embolic events, and infective endocarditis [1, 4]. Pregnancy in patients with RHD complicated by right ventricular dysfunction and pulmonary hypertension is associated with high maternal and fetal morbidity and mortality and requires antenatal consultation with cardiology and obstetrics [1]. Interventional treatment is warranted when patients with severe valvular lesions become symptomatic [5]. The choice of mechanical vs. bioprosthetic material for valve replacement depends on the patient's age, pathologic anatomy of the MV and ability to safely adhere to anticoagulant treatment [6-7]. For mitral stenosis, percutaneous mitral balloon commissurotomy has replaced surgical commissurotomy in patients with suitable MV anatomy and yields excellent mid-term results, with a 50-60\% event-free outcome at 10-year follow-up in a recent retrospective study of 1024 patients undergoing this procedure [8]. In patients with MV anatomy unsuitable for percutaneous commissurotomy, valve replacement involves considerations of type of valve (mechanical or bio-prosthetic) patient age, pathology of the MV and capacity to safely adhere to anticoagulant therapy [7].

\section{Clinical Course}

Echocardiographic criteria and lack of ischemic heart disease on coronary angiography supported the diagnosis of rheumatic mitral stenosis-as the etiology of our patient's cardiac pathology and heart failure. His ECG suggesting severely elevated right ventricular systolic pressure was confirmed by en echocardiography. He received judicious diuresis, given preload dependency in severe mitral stenosis, and received in-patient monitoring for arrhythmias which were as not detected on telemetry [9]. Because of findings of a prior stroke on head CT, and carotid artery stenosis, he was started on secondary prevention for stroke with aspirin and a high-intensity statin. The patient's markedly calcified mitral valve precluded commissurotomy and as a military veteran, he was transferred to a regional Veterans Administration hospital for mitral valve replacement. After successful cessation of smoking, his mitral valve was replaced, and he experienced early resolution of symptoms.

\section{Acknowledgments}

Financial/nonfinancial disclosures: None declared

\section{References}

1. Marijon E, Mirabel M, Celermajer DS, et al. (2012). Rheumatic heart disease. Lancet. 379(9819):953-964.

2. Shah, S. N. \& Sharma, S. (2019). Mitral Stenosis. In StatPearls. Treasure Island (FL): StatPearls Publishing.

3. Watkins DA, Johnson CO, Colquhoun SM, et al. (2017). Global, Regional, and National Burden of Rheumatic Heart Disease, 1990-2015. N Engl J Med. 377(8):713-722.

4. Remenyi B, Wilson N, Steer A, et al. (2012). World Heart Federation criteria for echocardiographic diagnosis of rheumatic heart disease--an evidence-based guideline. Nat Rev Cardiol. 9(5):297-309.

5. Bonow RO, Carabello BA, Chatterjee K, et al. (2008). Focused update incorporated into the ACC/AHA 2006 guidelines for the management of patients with valvular heart disease: a report of the American College of Cardiology/American Heart Association Task Force on Practice Guidelines (Writing Committee to Revise the 1998 Guidelines for the Management of Patients With Valvular Heart Disease): endorsed by the Society of Cardiovascular Anesthesiologists, Society for Cardiovascular Angiography and Interventions, and Society of Thoracic Surgeons. Circulation. 118(15):523-661.

6. Enriquez-Sarano M, Akins CW, Vahanian A. (2009). Mitral regurgitation. Lancet. 373(9672):1382-94.

7. North RA, Sadler L, Stewart AW, et al. (1999). Long-term survival and valve-related complications in young women with cardiac valve replacements. Circulation. 99(20):2669-2676.

8. Iung B, Garbarz E, Michaud P, et al. (1999). Late results of percutaneous mitral commissurotomy in a series of 1024 patients. Analysis of late clinical deterioration: frequency, anatomic findings, and predictive factors. Circulation. 99(25):3272-3278.

9. Boon NA, Bloomfield P. (2002). The medical management of valvar heart disease. Heart. 395-400.

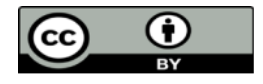

This work is licensed under Creative Commons Attribution 4.0 License
Ready to submit your research? Choose Auctores and benefit from:

$>$ fast, convenient online submission

$>$ rigorous peer review by experienced research in your field

$>$ rapid publication on acceptance

$>$ authors retain copyrights

$>$ unique DOI for all articles

$>$ immediate, unrestricted online access

At Auctores, research is always in progress.

Learn more auctoresonline.org/journals/international-journal-of-clinicalcase-reports-and-reviews 